\title{
Autophagy-associated immune responses and cancer immunotherapy
}

\author{
Hongming Pan ${ }^{1,2, *}$, Liuxi Chen ${ }^{1,2, *}$, Yinghua $X u^{1,2}$, Weidong Han ${ }^{1,2}$, Fang Lou ${ }^{1,2}$, \\ Weiqiang $\mathrm{Fei}^{2}$, Shuiping $\mathrm{Liu}^{2}$, Zhao $\mathrm{Jing}^{2}$ and Xinbing Sui ${ }^{1,2}$ \\ 1 Department of Medical Oncology, Sir Run Run Shaw Hospital, Zhejiang University, Hangzhou, China \\ 2 Biomedical Research Center and Key Laboratory of Biotherapy of Zhejiang Province, Hangzhou, China \\ * These authors have contributed equally to this work
}

Correspondence to: Xinbing Sui, email: hzzju@aliyun.com

Keywords: autophagy, immune, cancer immunotherapy

Received: September 16, 2015 Accepted: January 06, 2016

Published: January 13, 2016

\section{ABSTRACT}

Autophagy is an evolutionarily conserved catabolic process by which cellular components are sequestered into a double-membrane vesicle and delivered to the lysosome for terminal degradation and recycling. Accumulating evidence suggests that autophagy plays a critical role in cell survival, senescence and homeostasis, and its dysregulation is associated with a variety of diseases including cancer, cardiovascular disease, neurodegeneration. Recent studies show that autophagy is also an important regulator of cell immune response. However, the mechanism by which autophagy regulates tumor immune responses remains elusive. In this review, we will describe the role of autophagy in immune regulation and summarize the possible molecular mechanisms that are currently well documented in the ability of autophagy to control cell immune response. In addition, the scientific and clinical hurdles regarding the potential role of autophagy in cancer immunotherapy will be discussed.

\section{INTRODUCTION}

The term autophagy was a cellular 'self-eating' process by which intracytosolic components or organelles are sequestered into vacuolar compartments and subsequently delivered to the lysosome for bulk degradation and recycling $[1,2]$. Currently, there are three major types of autophagy in eukaryotic cells, including macroautophagy, chaperone-mediated autophagy (CMA), and microautophagy [3]. Macroautophagy (hereafter referred to as autophagy in this review) is a multi-step process which regulates the turnover of cytosolic proteins and damaged or superfluous organelles. The autophagic process includes at least four distinct stages (i) initiation, which involves the formation of the phagophore through complex interaction of the autophagic protein Atg6 (Beclin 1) and class III phosphatidylinositol 3-kinase (PtdIns3K), along with intracytosolic components; (ii) elongation, where the phagophore is elongated and sequesters the cytoplasmic constituents by the microtubule-associated protein 1 light chain 3 (LC3; Atg8) and the Atg12-Atg5Atg16L conjugation systems; (iii) maturation, resulting in encapsulation of cellular components which associates with complex; (iv) ultimate degradation of the engulfed components in the lysosomes (Figure 1A) [4, 5].

A series of signaling pathways have been implicated in autophagic process during cancer initiation and development. The central checkpoints in autophagy induction are the phosphatidylinositol 3-kinase (PI3K)/ mammalian target of rapamycin (mTOR) and AMP activated protein kinase (AMPK) signaling pathways (Figure 1B) [6,7]. Activated the class I PI3K generates phosphatidylinositol-3, 4, 5-triphosphate, which binds to the pleckstrin homology domain of Akt and PDK1 at the plasma membrane. As a result, Akt signaling pathway is activated. Once activated, Akt may stimulate multiple downstream targets, including the mTOR pathway which negatively regulates autophagy [8]. Conversely, AMPK, the primary energy-sensing kinase of the cell which is activated during hypoxia or energy depletion by increased ratios of AMP to ATP, can stimulate autophagy through mTOR in a TSC1/2 dependent pathway $[9,10]$. In addition, endoplasmic reticulum (ER) stress may induce autophagy through the PERK-eukaryotic initiation factor $2 \alpha$ (eIF2 $\alpha)$-AEF4 and IRE1-JNK1 pathways $[11,12]$. Hypoxia promotes the activation of autophagy through 
upregulation of BNIP3 [13]. Rag and Raf/MEK/ERK signaling pathways contribute to amino acid depletion induced autophagy [14]. DNA damage and energy depletion also respectively stimulate autophagy via p53 or LKB1 signal, the upstream target of mTOR.

Autophagy is involved in various cell aspects of biological processes, including cell survival, cell death, differentiation, senescence and metabolism [15]. Autophagy is constitutively active in the normal cells, which promotes the turnover of unfolded proteins and damaged organelles to maintain cellular homeostasis [16]. When the cells are subjected to stressful conditions including starvation, growth factors deprivation or high energetic requirements, autophagy can function as a survival signal to restore metabolic homeostasis and protect the cells from the damages from such conditions. However, persistent or excessive autophagy is also shown to promote cell death, termed autophagy-associated cell death or type II programmed cell death in contrast to type I programmed cell death or apoptosis $[17,18]$.

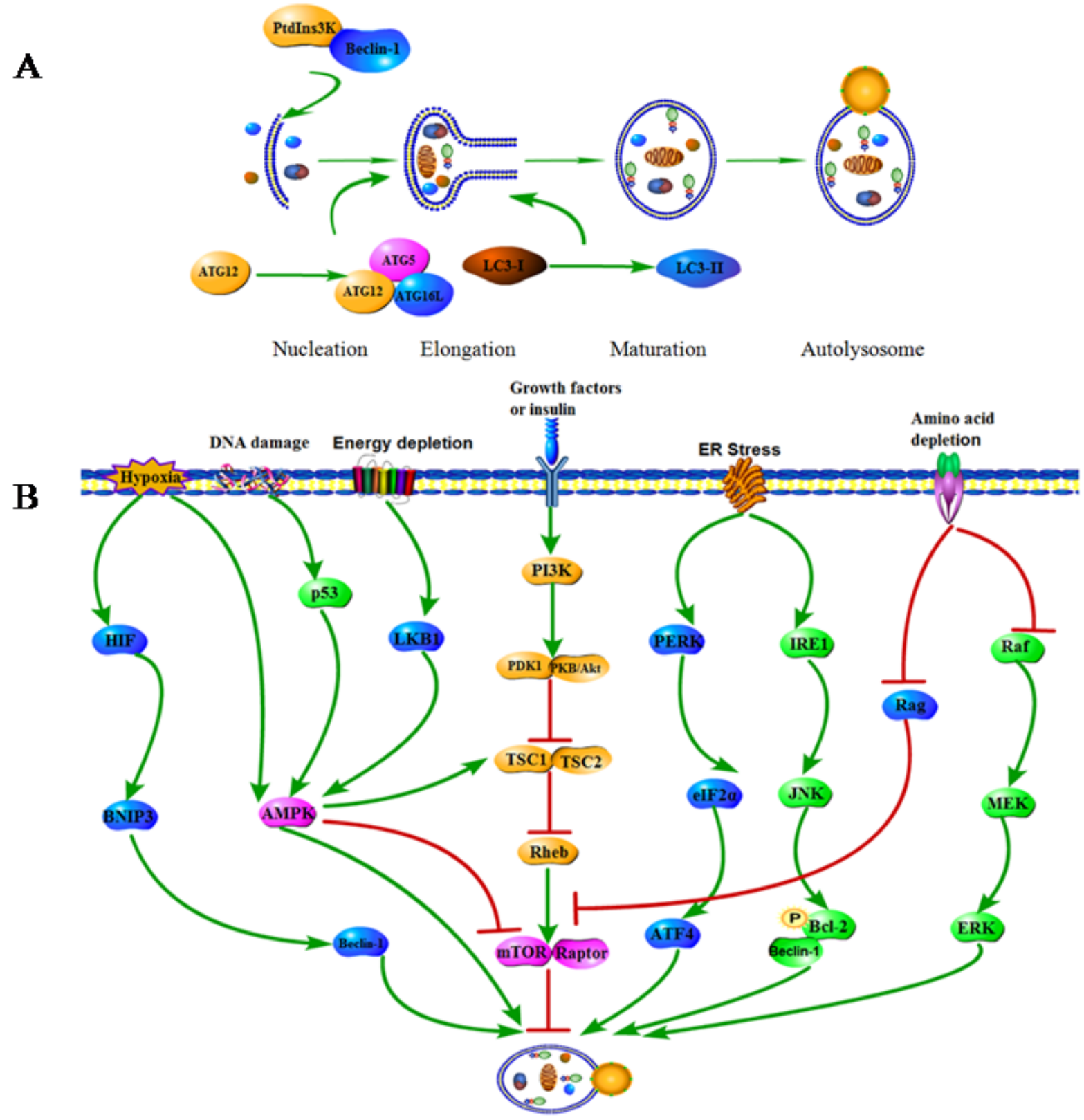

Figure 1: Phases and molecular regulation of autophagy. A. The four main phases of autophagy. Autophagy proceeds through several phases, including the initiation, elongation, maturation and ultimate degradation of the membrane and its contents within the lysosomes. The class III PI3P kinase binds to Beclin 1 to promote the initiation of autophagy. Atg12-Atg5-Atg16L and LC3 conjugation systems contribute to the elongation of the isolation membrane and autophagosome closure. B. Autophagy-associated signaling pathways in cancer. Autophagy can be activated in response to multiple stresses during cancer progression, including nutrient deprivation, endoplasmic reticulum stress, hypoxia, glucose/energy depletion and other diverse stresses. The central signalling molecules in determining the levels of autophagy in cancer cells are AMPK-PI3K/Akt/mTOR pathways. 
Recently, several studies have shown that autophagy also participates in the regulation of immune response. Autophagy may deliver cytoplasmic components to lysosomes, therefore, contribute to cytoplasmic immune recognition and response [19]. In addition, autophagy and autophagy-associated genes influence innate and adaptive immunity through regulating antigen processing and presentation [20]. Thus, autophagy is now widely recognized as an important regulator in immune recognition and responsiveness. However, how autophagy and autophagy-associated genes regulate antigen presentation and immune response is still less well acknowledged. Although the relationship between autophagy and cancer cell immune is quite complicated, and has not been well elucidated, understanding the novel role of autophagy may allow us to develop potential immunotherapeutic approaches against cancer.

\section{AUTOPHAGY AND CANCER IMMUNOLOGY}

Recently, the role of autophagy has been expanded to immune systems, which in turn regulate innate and adaptive immune responses. Rapidly accumulating evidence has provided a link between stimulation of autophagy and cancer immune responses.

\section{Innate immunity-mediated autophagy and cancer immunology}

The innate immune response of autophagy is mainly involved in the conjunction of pathogen-associated molecular patterns (PAMPs) and damage-associated molecular patterns (DAMPs) with pattern recognition receptors (PRR). PRR include Toll-like receptors (TLRs), nucleotide oligomerization domain (NOD)-like receptors (NLRs), and receptors for cytokines such as interferon (IFN), tumor necrosis factor (TNF)- $\alpha$ [21, 22]. Autophagy can be up-regulated by the activation of these innate immune receptors (Figure 2).

\section{TLRs}

TLRs are a series of innate receptors which are expressed in a wide variety of cancer cells and play a crucial role in several innate immune responses by regulating autophagy. TLR2 was reported to mediate phagocytosis and autophagy to enhance host innate immune response through the activation of c-jun $\mathrm{N}$-terminal kinase (JNK) and extracellular signal-regulated kinase (ERK) signaling pathways [23, 24]. In response to lipopolysaccharide (LPS) or alpha-GalCer analog (CCL34) treatment, TLR4 promoted macrophages through inducing expression of mitogen-activated protein kinases (ERK, JNK, p38 and RIP1) and some TLR4-downstream cytokines such as TNF-a, IL-6 and iNOS $[25,26]$. TLR7 stimulated the autophagy in a myeloid differentiation factor 88 (MyD88)-dependent manner, resulting in eliminating intracellular microbes, even when the target pathogen was normally not associated with TLR7 signalling [27]. In addition to TLRs, TLR agonist prointerleukin-1 $\beta$ (IL-1 $\beta$ ) could be specifically sequestered into autophagosomes, whereas further activation of autophagy in antigen-presenting cells [28]. Taken together, TLRs and its agonists play an important role in the activation of autophagy. However, little is known about the potential interaction between TLR signaling and autophagy in cancer immunology. The DNA damageregulated autophagy modulator DRAM1 functioned to mediate pathogen recognition by TLR-MYD88-NF- $\mathrm{KB}$ innate immune sensing pathway to activate selective autophagy [29]. Graphene oxide (GO), a nanomaterial with burgeoning bioapplications, may trigger autophagy to confer antitumor immune response through MyD88and TNF receptor-associated factor 6 (TRAF6)-associated TLR-4/9 signaling pathways. Injection of GO alone into immunocompetent mice bearing the CT26 colon tumors not only suppressed the tumor progression but also enhanced autophagy and immune responses within the tumor bed [30]. Interestingly, there is a controversial report regarding the role of TLRs-associated autophagy in cancer development and immunology. The results from Zhan's laboratory demonstrated that the induction of autophagy contributed to TLR4- and TLR3-triggered progression of lung cancer cells by enhancing the production of chemokines and immunosuppressive factors via the promotion of TRAF6 ubiquitination [31].

\section{NLRs}

NLRs are a family of cytoplasmic molecules responsible for intracellular bacteria sensing and constitute an essential component of the host innate immune system. Nod1 and Nod2 are the first NLRs identified as microbialassociated molecular patterns (MAMP) detectors. Both Nod1 and Nod2 can directly stimulate autophagy by interacting at the plasma membrane with ATG16L1, an essential component for autophagosome formation [22]. Reports concerning the importance of NLR-mediated autophagy in neoplasia or possible cancer immune are very limited. Both Nod1 and Nod2 play a key role in realization of innate/adaptive immune responses and autophagy, and their gene polymorphisms may be associated with a variety of cancer types [32]. NOD1 is also an intracellular immune receptor that senses peptidoglycan from Gramnegative bacterial peptidoglycan (PG) and responds by inducing autophagy and activating NF- $\mathrm{KB}$, leading to inflammation-mediated Helicobacter pylori (H. pylori) clearance which is considered as a important risk factor for gastric carcinogenesis [33].

\section{Others}

Recently, interferon regulatory factor 8 (IRF8) was reported to be a major regulator for autophagy maturation and innate immune responses through directly promoting autophagosome formation and lysosomal fusion [34]. 


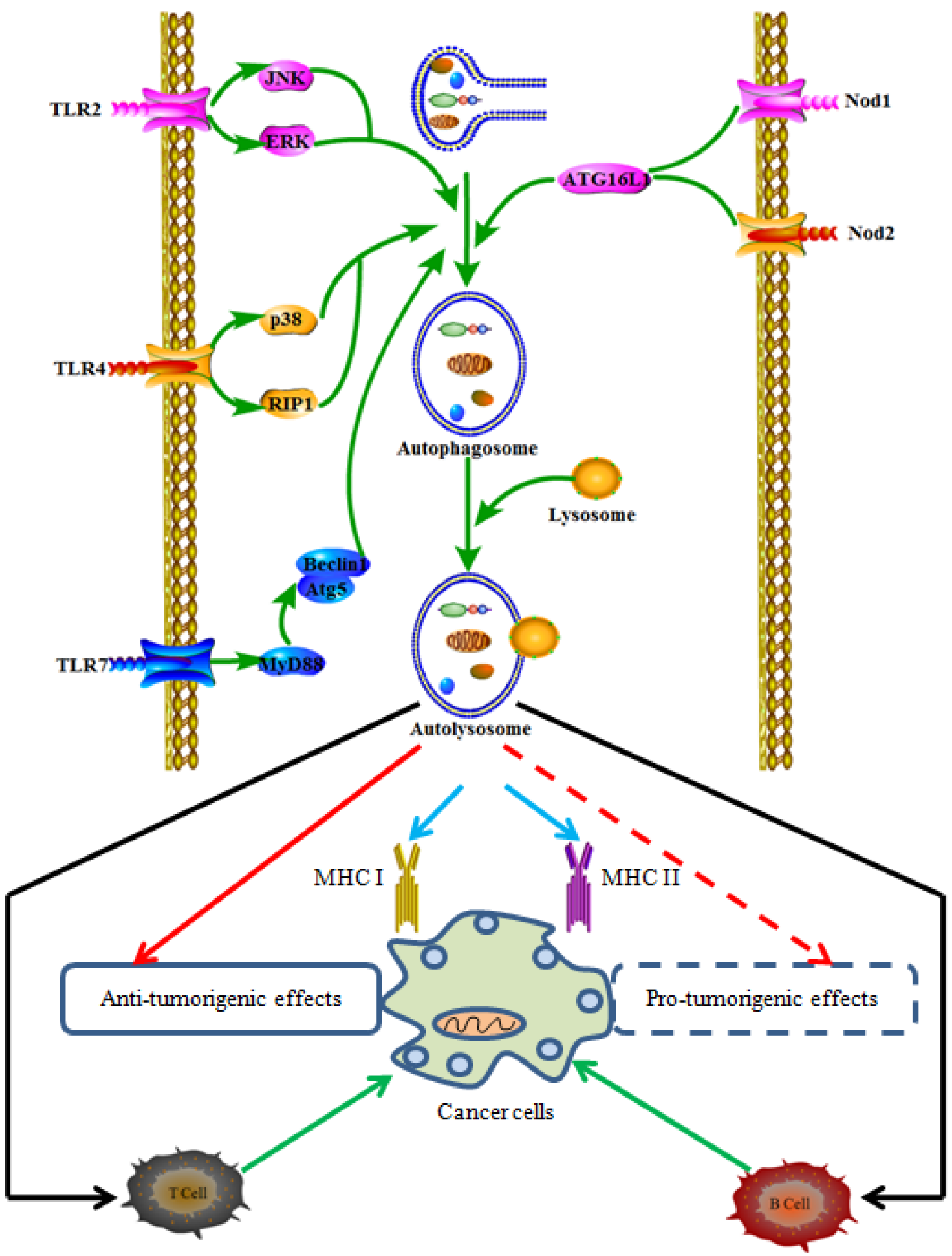

Figure 2: The relationship between autophagy-associated immune signals and cancer immune responses. Activation of innate and adaptive receptors can regulate autophagy through different signaling pathways and act in the recruitment of autophagy proteins to phagosomal membrane, resulting in anti-tumorigenic effects or pro-tumorigenic effects. 
IFN- $\gamma$ was proved to trigger autophagy via p38 MAPK signaling pathway, which contributed to cell-autonomous innate immunity [35]. Importantly, IFN- $\gamma$ can inhibit inflammation-associated gastric carcinogenesis by inducing epithelial cell autophagy and T-cell apoptosis [36]. Recent studies show that autophagy is also a crucial regulator of innate immunity cytokines such as interleukin (IL). Autophagy has a potentially pivotal role to regulate IL-23 secretion and innate T cell responses through effects on IL-1 secretion [37]. Autophagy also may modulate Borrelia burgdorferi-induced production of IL-1 $\beta$ and attenuation of IL-1 $\beta$ in immortalized cells is apparently a crucial step in viral immune evasion and initiation of malignancy [38, 39]. Melanoma differentiation associated gene-7(mda-7)/IL-24 is a unique member of the IL-10 gene family that stimulates antitumor immune response to promote cancer-targeted toxicity [40]. In addition, autophagic proteins $\mathrm{LC} 3 \mathrm{~B}$ and beclin 1 can regulate innate immune responses by inhibiting the release of mitochondrial DNA which is depended on the NALP3/ NLRP3 inflammasome and mitochondrial reactive oxygen species (ROS) [41, 42]. Taken together, these studies have raised additional mechanisms that innate immune receptors-associated autophagy displays different regulation on cancer cells.

\section{Adaptive immunity-mediated autophagy and cancer immunology}

\section{Autophagy and antigen presentation}

Cross-presentation is defined as a process by which the certain exogenous antigens are taken up, processed, and then presented to antigen-specific $\mathrm{T}$ cells by host professional antigen-presenting cells (APC), thus, crosspresentation is very critical for the induction of adaptive immunity [43]. Currently, autophagy has been identified to play a novel role in antigen sequestration and delivery to MHC class I molecules for cross-presentation [44]. Autophagy-mediated elimination was critical for MHC I-mediated cross-presentation and blocking autophagy resulted in a drastic increase in the number of intracellular bacteria and Chlamydia-positive DCs [45]. TNF- $\alpha$ was observed to induce autophagy to enable the processing and presentation of mitochondrial antigens at the cell surface by MHC class I molecules [46]. Several researches reported the relationship between MHC I-mediated autophagy and cancer immune response. Crosspresentation of tumor associated antigens by MHC class I molecules could be regulated by autophagy-mediated lysosomal proteolysis and proteasomal degradation [47]. The direct evidence from $\mathrm{Li}$, et al. showed that autophagy was involved in the regulation of MHC-I antigen expression, through which autophagy could play different roles in tumor immunity: enhancing the cytolysis of CTL to melanoma cells at the early stage of melanoma, but impairing the cytolysis at the late stage [48].

Different from endogenous MHC class I peptides which are primarily generated by proteasomes in the cytosol, the endosomal/lysosomal system is responsible for the processing of MHC-II presentation. During MHC class II presentation, exogenous antigens are processed in endolysosomal compartments where they are degraded by lysosomal proteases and then fused with MHC class II loading compartment (MIIC), resulting in delivering cytosolic proteins to $\mathrm{MHC}$ class II molecules for immune surveillance [49]. Autophagy can deliver cytoplasmic material to lysosomes, therefore, contributes to cytoplasmic antigen presentation of $\mathrm{MHC}$ class II molecules [50]. Targeting of the Influenza Matrix Protein 1 (MP1) to autophagosomes via fusion to the autophagosome-associated protein Atg8/LC3 led to strongly enhanced MHC class II presentation to $\mathrm{CD}^{+} \mathrm{T}$ cell clones [51]. Similarly, autophagy may subject the cell to an enhanced immune surveillance by $\mathrm{CD}^{+} \mathrm{T}$ cells in response to stressful conditions $[52,53]$. These studies establish clear evidence that autophagy facilitates MHCII presentation of peptides from intracellular proteins in general way and indicate that autophagy might act as a potential mechanism for the cross-presentation of tumor antigen onto MHC molecules. However, how regulation of the autophagy pathways in cancer cells influences MHC molecules has not yet been thoroughly investigated.

\section{Autophagy in the development and function of $T$ cells and $B$ cells}

Beyond its role in antigen presentation, autophagy also shapes adaptive immunity through its contribution to the development and function of lymphocytes including $\mathrm{T}$ cells and B cells.

\section{Autophagy in T Cells}

$\mathrm{T}$ cells are particularly dependent on autophagy for their homeostasis and activation. Both $\mathrm{CD}^{+}$and $\mathrm{CD}^{+} \mathrm{T}$ cells are tightly regulated by positive and negative modulators of signaling pathways downstream of the $\mathrm{T}$ cell antigen receptor (TCR). Basal autophagy maintains organelle homeostasis in $\mathrm{T}$ cells and can be induced following TCR stimulation [54, 55]. Moreover, several autophagy associated proteins are involved in the activation of T cells. The deletion of Atg3, Atg5, Atg7, Beclin-1 and the class III phosphoinositide 3-kinase Vps34, the positive mediators of autophagy, caused impaired autophagy and defective $\mathrm{T}$ cell homeostasis by inhibiting T-cell survival through quality control of mitochondria $[54,56,57]$. Autophagy had different effects in the cell survival of HIV-infected T cells and "bystander" $\mathrm{T}$ cells, and it was altered differently by HIV infection. HIV-1 viral infectivity factor can interact with LC3B and inhibit autophagy [58]. However, HIV-1 Tat protein was also able to stimulate autophagy through increasing BAG3 levels in human glial cells [59]. Increasing evidence has suggests a link between the deregulation of autophagy 
and regulatory $\mathrm{T}$ cell-controlling anticancer immunity. Autophagy was induced in $\mathrm{CD}^{+} \mathrm{T}$ cells via $\mathrm{JNK}$ and Vps34 and played an important role for the growth factor-withdrawal cell death [60]. Autophagy also partly regulated the helper $\mathrm{T}$ lymphocytes (HTLs) antitumor responses against tumors expressing c-Met [61]. However, autophagy has not only pro-death but also pro-survival roles in T cells depending on cellular contexts and stimuli. The expression of autophagy-associated proteins in the peripheral site of oral squamous cell carcinoma (OSCC) significantly correlated with an increase in the infiltration of $\mathrm{T}$ cells and several unfavorable clinicopathological parameters, which indicated that autophagy may actively mobilize immune cells toward the cancer bed and contribute to malignant potential and an unfavorable prognosis [62]. In $\mathrm{KRas}^{\mathrm{G} 12 \mathrm{D}}$-driven lung cancer, Atg5regulated autophagy bestowed cancer cells a significant survival advantage and accelerated tumor progression by increasing oncogenesis maps to regulatory T cells [63]. Hypericin-based photodynamic therapy (Hyp-PDT)induced autophagy dampened key processes that underlie immunogenic cell death (ICD) and the elicitation of anticancer immune responses by suppression of immune effectors $\mathrm{CD}^{+}$and $\mathrm{CD}^{+} \mathrm{T}$ lymphocyte, thus facilitated cancer cells escape from immunosurveillance [64]. Taken together, these studies have raised a critical role for $\mathrm{T}$ cells-associated autophagy in cancer immunology.

\section{Autophagy in B Cells}

Limited evidence exists that autophagy plays a complex role in B cells development and survival. The activation of autophagy was found to be a mechanism for survival of autoreactive B cells [65]. Moreover, Autophagy gene Atg5 was required for B cell development, B-1a B cell maintenance and plasma cell development and function [66, 67]. Atg5 deletion failed to transition between pro- and pre-B-cell stages in the bone marrow. RelA appeared to be pivotal in both classical and alternative activation pathways in EpsteinBarr virus (EBV)-transformed B cells, which was partly due to the induction of autophagy [68]. Tumor-derived autophagosomes (termed "DRibbles") could induce $B$ cell activation and the current study suggested that macrophages significantly enhanced DRibbles-induced B cell immune function by TLR4 and MyD88 signaling pathway [69]. Taken together, the current data from multiple groups have shown that autophagy functions as an important role in the development of certain subsets of $\mathrm{B}$ cells and B cell memory [70].

\section{AUTOPHAGY-MEDIATING CELL IMMUNITY} AND CANCER IMMUNOTHERAPY

Currently, immune-based therapies are attracting more and more attention in cancer treatment [71]. A variety of cancer immunotherapies, including vaccines and adoptive cell transfer, have been clinically applied [72]. Autophagy, a dynamic process of protein degradation, has been recently linked to cancer immunotherapy. Targeting autophagy-dependent cross-presentation and immune responses may provide us a promising therapeutic approach for cancer treatment, although the mechanisms underlying immunogenic potential of autophagy have not been well elucidated (Table 1).

\section{Autophagy as a pro-death mechanism}

Autophagy as a pro-death signal in the abnormal tumor microenvironment is an important mechanism that suppresses tumor progression and enhances anti-tumor immunity and response to therapies. Alpha-alumina $\left(\alpha-\mathrm{Al}_{2} \mathrm{O}_{3}\right)$ nanoparticles could induce efficient autophagydependent cross-presentation through delivering antigens to autophagosomes in DCs, which contributed to tumor regression [73]. Monobenzone augmented the processing and shedding of melanocyte-differentiation antigens by triggering melanosome autophagy, which induced cytotoxic human melanoma-reactive T cells and resulted in tumor suppression [74]. Autophagy protein p62encoding DNA vaccine was found to elicit antitumor and antimetastatic activity in five types of commonly used transplantable tumor models [75].

Basing on that certain cancer cells are highly dependent on folate metabolism, the functional mechanisms of MORAB-003 (farletuzumab), a humanized $\mathrm{mAb}$ against folate receptor alpha (FRa), was investigated. As a result, MORAB-003 induced sustained autophagy and suppressed cell proliferation in ovarian cancer models [76]. Recently, autophagosome-enriched vaccine named DRibbles, was demonstrated to eradicate 3LL Lewis lung tumors and significantly delay the growth of B16F10 melanoma, which is partly due to CLEC9A, a newly described C-type lectin receptor expressed by a subset of conventional DCs [77].

Conventional chemotherapies are particularly efficient when they elicit immunogenic cell death (ICD) which is accompanied by stereotyped molecular changes, including the pre-apoptotic exposure of calreticulin (CRT) on the cell surface, the lysosomal secretion of adenosine triphosphate (ATP) during the blebbing phase of apoptosis, and the post-apoptotic release of high mobility group box 1 (HMGB1) from dying cells [78, 79]. Autophagy upregulated the mannose-6-phosphate receptor (MPR) on the tumor cell surface and caused ICD via T cells activation [80]. Newcastle disease virus (NDV) infection was shown to prime adaptive antitumor immunity in orthotopic glioma through the induction of ICD as well as autophagy [81]. Autophagy may attract DCs and T lymphocytes into the tumor bed and promote the immunogenic release of ATP from dying cells, and autophagy deficits abolish the capacity of cancer cells to elicit an immune response [82]. Systemic chemotherapy 
Table 1: Therapeutic compounds and targets that modulate autophagy-dependent immune responses

\begin{tabular}{|l|l|l|l|l|l|}
\hline Compound & $\begin{array}{l}\text { Effect on } \\
\text { autophagy }\end{array}$ & Immunogenic responses & Mechanism & Types of cancer & References \\
\hline$\alpha-\mathrm{Al}_{2} \mathrm{O}_{3}$ & inducer & cross-presentation & unknown & Lung cancer & 73 \\
\hline Monobenzone & inducer & T cells & unknown & Melanoma & 74 \\
\hline $\begin{array}{l}\text { p62-encoding } \\
\text { DNA vaccine }\end{array}$ & inducer & unknown & unknown & $\begin{array}{l}\text { Melanoma, Lung } \\
\text { cancer and so on }\end{array}$ & 75 \\
\hline Farletuzumab & inducer & FRa & unknown & Ovarian cancer & 76 \\
\hline DRibble & inducer & DCs, cross-presentation & CLEC9A & $\begin{array}{l}\text { Lung cancer, } \\
\text { Melanoma }\end{array}$ & 77 \\
\hline MTX & inducer & DCs, T cells, ATP & PI3K, Akt & Melanoma & 83 \\
\hline BcG/cWs & inducer & TLR & JNK & Colon cancer & 84 \\
\hline IFN1 & inducer & innate immune & $\begin{array}{l}\text { JAK1-sTAT1 } \\
\text { and ReLA }\end{array}$ & CML & 85 \\
\hline CQ & inhibitor & DCs & $\begin{array}{l}\text { Endosomal } \\
\text { pathways }\end{array}$ & Breast cancer & 92 \\
\hline HCQ & inhibitor & B cells, CTL & unknown & $\begin{array}{l}\text { Lymphoma, } \\
\text { Melanoma }\end{array}$ & 93,94 \\
\hline
\end{tabular}

with the anthracycline Mitoxantrone (MTX) reduced the growth of autophagy-competent melanomas but not autophagy-deficient melanomas and this growth-inhibitory effect could be abolished by the combined depletion of $\mathrm{CD}^{+}$or $\mathrm{CD} 8^{+} \mathrm{T}$ lymphocytes, indicating that autophagydependent anticancer immune response determined the efficacy of MTX in melanoma [83]. BovisBacillus calmette-Guerin $(\mathrm{BcG} / \mathrm{cWs})$ is an effective antitumor immunotherapy agent and treatment with $\mathrm{BcG} / \mathrm{cWs}$ plus ionizing radiation (IR) resulted in the induction of autophagic cell death in colon cancer cells through JNK and TLR pathways [84].

Many cytokines are also closely related to the activation of autophagy and cancer immune. IFN- $\gamma$ not only mediated responses to bacterial infection and autoimmune disease but also functioned as an important tumor suppressor to inhibit gastric carcinogenesis by inducing epithelial cell autophagy and T-cell apoptosis [36]. IFN1 has been extensively studied as a treatment for patients with chronic myeloid leukemia (CML), however, the mechanism of anticancer activity of IFN1 is not well understood. The results from $\mathrm{Zhu}$, et al. showed that autophagy regulated IFN1-mediated cell death, and activation of JAK1-sTAT1 and ReLA signaling were required for this process [85]. These findings reveal immunogenic effect of autophagy and witnesses that autophagy may be evaluated as a novel target for cancer immunotherapies.

\section{Autophagy as a pro-survival mechanism}

Besides its potential to induce cell death, a prosurvival role is indicated in the process of autophagy following anticancer treatments.

On the one hand, the induction of autophagy may impair the anticancer immune responses and avail tumor cells to escape immune surveillance, resulting in tumor growth and cancer progression. The inhibition of Atg7 prevented intestinal tumor initiation through enhancing anticancer immune responses of $\mathrm{CD} 8^{+} \mathrm{T}$ cells [86]. The treatment of autophagy inducer rapamycin can promote metastasis of 4T1 cells in a tumor resection mouse model and this effect may be reversed by treatment with a DCbased cancer vaccine [87]. Epithelial-to-mesenchymal transition (EMT) may promote cancer cell invasion and metastasis, but its impact on immune surveillance has not been explored. Recently, it was shown that EMT transition exhibited attenuation in cytotoxic T lymphocytes (CTL)mediated tumor cell lysis along with the induction of autophagy, indicating EMT and autophagy function as conceptual realms for immunotherapeutic strategies to block immune escape [88].

On the other hand, autophagy also provides intrinsic resistance against anticancer therapy by reducing anticancer immune effector mechanisms. Autophagy plays a protective role against sepsis-induced $\mathrm{T}$ lymphocyte apoptosis and immunosuppression, thus, down-regulation of autophagy in $\mathrm{T}$ lymphocytes may result in enhanced apoptosis and decreased cell survival [89]. The activation of autophagy in hypoxic melanoma cells was proved to selectively degrade gap-junctional channel activity of connexin 43 (Cx43), leading to the destabilization of the immune synapse and the suppression of NK cell-mediated tumor cell killing [90]. The inhibition of autophagy augmented cytotoxicity in combination with several anticancer approaches and inhibited cancer progression in preclinical models. Administration of high dose interleukin 2 (HDIL-2) has durable antitumor effects for the patients with melanoma and renal cell carcinoma. However, the side effects restricted its clinical application. Recent study indicated that inhibiting autophagy by chloroquine (CQ) enhanced the efficacy of HDIL-2 immunotherapy and decreased toxicity for cancer patients [91]. CQ 
also blocked radiation-induced autophagy and drove breast cancer cells into a more rapid apoptotic and more immunogenic form of cell death by Dcs, although T-cell stimulation was unaffected [92]. Moreover, anti-CD20 nanoparticles carrying Hydroxychloroquine (HCQ) and Chlorambucil increased tumor cell killing in comparison to free cytotoxic agents or Rituximab [93]. Hypoxia-induced resistance of lung tumor to cytolytic T lymphocyte (CTL)mediated lysis was demonstrated to be associated with autophagy induction, and inhibition of autophagy by HCQ dramatically reduced tumor growth in B16-F10 tumorbearing mice and restored the susceptibility of hypoxic tumor cell to CTL-mediated lysis [94]. In line with these observations, hypoxia-induced autophagy impaired cancer cell susceptibility to Natural killer (NK)-mediated killing and the activation of autophagy in hypoxic cells was involved in selective degradation of the pro-apoptotic NK-derived serine protease granzyme B. Inhibition of autophagy by targeting Beclin 1 restored granzyme B levels in hypoxic cells and induced tumor regression by facilitating NK-mediated tumor cell killing [95, 96].

These studies provide us a promising therapeutic strategy to suppress the development of cancer cells and enhance the effects of anticancer approaches to overcome the antitumor immune resistance.

\section{CONCLUSIONS AND PERSPECTIVES}

Autophagy as a catabolic process has been implicated in multiple aspects of biological processes, including apoptosis, cell survival, senescence, metabolism and differentiation. Recently, several studies have shown that autophagy also participates in homeostatic regulation of immune responses. Advances over the past few years have expanded the scope of autophagy's role in immunity from its original incarnation as a catabolic mechanism to a full-range immunological process that participates in innate and adaptive immunity.

Currently, preclinical and clinical studies have identified the possible application strategy of autophagy as an immunotherapy. Autophagosome-enriched vaccines have been found to induced cytotoxic immune cells and elicit antitumor/antimetastatic activity [75, 77]. Targeting autophagy by nanoparticles or cytokines could serve as new therapies in the development of anticancer immunotherapy $[73,85]$. In addition, optimal combination of autophagy-based inducer or inhibitor with various therapeutic strategies including chemotherapy, gene therapy, and other types of cellular therapies may represent an important approach by eliciting immunogenic cell death in current cancer therapeutics [73, 85].

Although some results from certain studies are encouraging, several fundamental questions about immunogenic regulation and autophagy remain to be answered. Firstly, the question whether we should try to enhance or inhibit autophagy in cancer immunotherapy is not straightforward since it might vary according to cell type and the cellular context. When and how autophagy can be pro-survival and pro-death should be carefully interpreted in the future. The second critical challenge is determining the roles of autophagy-mediated immune response and possible mechanisms. Although a large number of evidence supports that immunogenic cells are dependent on autophagy for their homeostasis and activation, biological functions and precise molecular mechanism that is involved in the process remain unclear. Thirdly, the treatment of CQ or HCQ can inhibit autophagy-related survival function and exert their anticancer action in combination with several immunotherapeutic strategies. However, the anticancer ability of CQ and its derivative might not only be due to inhibit the final degradative step of autophagy. CQ or HCQ may also affect other pathways such as lysosomal membrane permeabilization [97, 98], which should be considered in the ongoing studies where CQ or HCQ are used as an autophagy inhibitor. A more detailed understanding the novel immunogenic function of autophagy will be critical in the future.

\section{ACKNOWLEDGMENTS}

This study is supported by grants from National Natural Science Foundation of China (grant No. 81301891 ) and Zhejiang province science and technology project of TCM (grant No. 2015ZB033).

\section{CONFLICTS OF INTEREST}

The authors declare no conflict of interest.

\section{REFERENCES}

1. Yang $\mathrm{Z}$ and Klionsky DJ. Eaten alive: a history of macroautophagy. Nat Cell Biol. 2010; 12:814-822.

2. Klionsky DJ. Ancient autophagy. Autophagy. 2013; 9:445446.

3. Sui X, Chen R, Wang Z, Huang Z, Kong N, Zhang M, Han W, Lou F, Yang J, Zhang Q, Wang X, He C and Pan $\mathrm{H}$. Autophagy and chemotherapy resistance: a promising therapeutic target for cancer treatment. Cell Death Dis. 2013; 4:e838.

4. Fullgrabe J, Klionsky DJ and Joseph B. The return of the nucleus: transcriptional and epigenetic control of autophagy. Nat Rev Mol Cell Biol. 2014; 15:65-74.

5. Feng Y, Yao Z and Klionsky DJ. How to control selfdigestion: transcriptional, post-transcriptional, and posttranslational regulation of autophagy. Trends Cell Biol. 2015; 25:354-363.

6. Marx J. Autophagy: is it cancer's friend or foe? Science. 2006; 312:1160-1161. 
7. Narita M, Young AR, Arakawa S, Samarajiwa SA, Nakashima T, Yoshida S, Hong S, Berry LS, Reichelt S, Ferreira M, Tavare S, Inoki K, Shimizu S and Narita M. Spatial coupling of mTOR and autophagy augments secretory phenotypes. Science. 2011; 332:966-970.

8. Shintani T and Klionsky DJ. Autophagy in health and disease: a double-edged sword. Science. 2004; 306:990995.

9. Rabinowitz JD and White E. Autophagy and metabolism. Science. 2010; 330:1344-1348.

10. Koren I and Kimchi A. Cell biology. Promoting tumorigenesis by suppressing autophagy. Science. 2012; 338:889-890.

11. Jiang Q, Li F, Shi K, Wu P, An J, Yang Y and Xu C. Involvement of p38 in signal switching from autophagy to apoptosis via the PERK/eIF2alpha/ATF4 axis in selenitetreated NB4 cells. Cell death \& disease. 2014; 5:e1270.

12. Sui X, Kong N, Ye L, Han W, Zhou J, Zhang Q, He C and Pan H. p38 and JNK MAPK pathways control the balance of apoptosis and autophagy in response to chemotherapeutic agents. Cancer letters. 2014; 344:174-179.

13. Hu YL, DeLay M, Jahangiri A, Molinaro AM, Rose SD, Carbonell WS and Aghi MK. Hypoxia-induced autophagy promotes tumor cell survival and adaptation to antiangiogenic treatment in glioblastoma. Cancer research. 2012; 72:1773-1783.

14. Kim JH, Hong SK, Wu PK, Richards AL, Jackson WT and Park JI. Raf/MEK/ERK can regulate cellular levels of LC3B and SQSTM1/p62 at expression levels. Experimental cell research. 2014; 327:340-352.

15. Bernard A and Klionsky DJ. Autophagosome formation: tracing the source. Developmental cell. 2013; 25:116-117.

16. Inguscio V, Panzarini E and Dini L. Autophagy Contributes to the Death/Survival Balance in Cancer PhotoDynamic Therapy. Cells. 2012; 1:464-491.

17. Cecconi $\mathrm{F}$ and Levine B. The role of autophagy in mammalian development: cell makeover rather than cell death. Developmental cell. 2008; 15:344-357.

18. Glick D, Barth S and Macleod KF. Autophagy: cellular and molecular mechanisms. The Journal of pathology. 2010; 221:3-12.

19. English L, Chemali M, Duron J, Rondeau C, Laplante A, Gingras D, Alexander D, Leib D, Norbury C, Lippe R and Desjardins M. Autophagy enhances the presentation of endogenous viral antigens on MHC class I molecules during HSV-1 infection. Nature immunology. 2009; 10:480-487.

20. Crotzer VL and Blum JS. Autophagy and adaptive immunity. Immunology. 2010; 131:9-17.

21. Feng CG, Zheng L, Jankovic D, Bafica A, Cannons JL, Watford WT, Chaussabel D, Hieny S, Caspar P, Schwartzberg PL, Lenardo MJ and Sher A. The immunityrelated GTPase Irgm1 promotes the expansion of activated CD4+ T cell populations by preventing interferon-gamma- induced cell death. Nature immunology. 2008; 9:12791287.

22. Travassos LH, Carneiro LA, Ramjeet M, Hussey S, Kim YG, Magalhaes JG, Yuan L, Soares F, Chea E, Le Bourhis L, Boneca IG, Allaoui A, Jones NL, et al. Nod1 and Nod2 direct autophagy by recruiting ATG16L1 to the plasma membrane at the site of bacterial entry. Nature immunology. 2010; 11:55-62.

23. Fang L, Wu HM, Ding PS and Liu RY. TLR2 mediates phagocytosis and autophagy through JNK signaling pathway in Staphylococcus aureus-stimulated RAW264.7 cells. Cellular signalling. 2014; 26:806-814.

24. Anand PK, Tait SW, Lamkanfi M, Amer AO, Nunez G, Pages G, Pouyssegur J, McGargill MA, Green DR and Kanneganti TD. TLR2 and RIP2 pathways mediate autophagy of Listeria monocytogenes via extracellular signal-regulated kinase (ERK) activation. The Journal of biological chemistry. 2011; 286:42981-42991.

25. Xu Y, Jagannath C, Liu XD, Sharafkhaneh A, Kolodziejska $\mathrm{KE}$ and Eissa NT. Toll-like receptor 4 is a sensor for autophagy associated with innate immunity. Immunity. 2007; 27:135-144.

26. Hung LC, Lin CC, Hung SK, Wu BC, Jan MD, Liou SH and Fu SL. A synthetic analog of alpha-galactosylceramide induces macrophage activation via the TLR4-signaling pathways. Biochemical pharmacology. 2007; 73:19571970.

27. Delgado MA, Elmaoued RA, Davis AS, Kyei G and Deretic V. Toll-like receptors control autophagy. The EMBO journal. 2008; 27:1110-1121.

28. Harris J, Hartman M, Roche C, Zeng SG, O'Shea A, Sharp FA, Lambe EM, Creagh EM, Golenbock DT, Tschopp J, Kornfeld H, Fitzgerald KA and Lavelle EC. Autophagy controls IL-1beta secretion by targeting pro-IL-1beta for degradation. The Journal of biological chemistry. 2011; 286:9587-9597.

29. van der Vaart M, Korbee CJ, Lamers GE, Tengeler AC, Hosseini R, Haks MC, Ottenhoff TH, Spaink HP and Meijer AH. The DNA damage-regulated autophagy modulator DRAM1 links mycobacterial recognition via TLP-MYD88 to authophagic defense. Cell host \& microbe. 2014; 15:753767.

30. Chen GY, Chen CL, Tuan HY, Yuan PX, Li KC, Yang HJ and $\mathrm{Hu}$ YC. Graphene oxide triggers toll-like receptors/ autophagy responses in vitro and inhibits tumor growth in vivo. Advanced healthcare materials. 2014; 3:1486-1495.

31. Zhan Z, Xie X, Cao H, Zhou X, Zhang XD, Fan H and Liu Z. Autophagy facilitates TLR4- and TLR3-triggered migration and invasion of lung cancer cells through the promotion of TRAF6 ubiquitination. Autophagy. 2014; 10:257-268.

32. Kutikhin AG. Role of NOD1/CARD4 and NOD2/ CARD15 gene polymorphisms in cancer etiology. Human immunology. 2011; 72:955-968. 
33. Suarez G, Romero-Gallo J, Piazuelo MB, Wang G, Maier RJ, Forsberg LS, Azadi P, Gomez MA, Correa P and Peek RM, Jr. Modification of Helicobacter pylori Peptidoglycan Enhances NOD1 Activation and Promotes Cancer of the Stomach. Cancer research. 2015; 75:1749-1759.

34. Gupta M, Shin DM, Ramakrishna L, Goussetis DJ, Platanias LC, Xiong H, Morse Iii HC and Ozato K. IRF8 directs stress-induced autophagy in macrophages and promotes clearance of Listeria monocytogenes. Nature communications. 2015; 6:6379.

35. Matsuzawa T, Fujiwara E and Washi Y. Autophagy activation by interferon-gamma via the p38 mitogenactivated protein kinase signalling pathway is involved in macrophage bactericidal activity. Immunology. 2014; 141:61-69.

36. Tu SP, Quante M, Bhagat G, Takaishi S, Cui G, Yang XD, Muthuplani S, Shibata W, Fox JG, Pritchard DM and Wang TC. IFN-gamma inhibits gastric carcinogenesis by inducing epithelial cell autophagy and T-cell apoptosis. Cancer research. 2011; 71:4247-4259.

37. Peral de Castro C, Jones SA, Ni Cheallaigh C, Hearnden CA, Williams L, Winter J, Lavelle EC, Mills KH and Harris J. Autophagy regulates IL-23 secretion and innate T cell responses through effects on IL-1 secretion. Journal of immunology. 2012; 189:4144-4153.

38. Buffen K, Oosting M, Mennens S, Anand PK, Plantinga TS, Sturm P, van de Veerdonk FL, van der Meer JW, Xavier RJ, Kanneganti TD, Netea MG and Joosten LA. Autophagy modulates Borrelia burgdorferi-induced production of interleukin-1beta (IL-1beta). The Journal of biological chemistry. 2013; 288:8658-8666.

39. Niebler M, Qian X, Hofler D, Kogosov V, Kaewprag J, Kaufmann AM, Ly R, Bohmer G, Zawatzky R, Rosl F and Rincon-Orozco B. Post-translational control of IL-1beta via the human papillomavirus type 16 E6 oncoprotein: a novel mechanism of innate immune escape mediated by the E3-ubiquitin ligase E6-AP and p53. PLoS pathogens. 2013; 9:e1003536.

40. Dash R, Bhutia SK, Azab B, Su ZZ, Quinn BA, Kegelmen TP, Das SK, Kim K, Lee SG, Park MA, Yacoub A, Rahmani M, Emdad L, Dmitriev IP, Wang XY, Sarkar D, et al. mda-7/IL-24: a unique member of the IL-10 gene family promoting cancer-targeted toxicity. Cytokine \& growth factor reviews. 2010; 21:381-391.

41. Nakahira K, Haspel JA, Rathinam VA, Lee SJ, Dolinay T, Lam HC, Englert JA, Rabinovitch M, Cernadas M, Kim HP, Fitzgerald KA, Ryter SW and Choi AM. Autophagy proteins regulate innate immune responses by inhibiting the release of mitochondrial DNA mediated by the NALP3 inflammasome. Nature immunology. 2011; 12:222-230.

42. Zhou R, Yazdi AS, Menu P and Tschopp J. A role for mitochondria in NLRP3 inflammasome activation. Nature. 2011; 469:221-225.

43. Baker K, Rath T, Lencer WI, Fiebiger E and Blumberg RS. Cross-presentation of IgG-containing immune complexes.
Cellular and molecular life sciences : CMLS. 2013; 70:1319-1334.

44. Li Y, Wang LX, Yang G, Hao F, Urba WJ and Hu HM. Efficient cross-presentation depends on autophagy in tumor cells. Cancer research. 2008; 68:6889-6895.

45. Fiegl D, Kagebein D, Liebler-Tenorio EM, Weisser T, Sens M, Gutjahr M and Knittler MR. Amphisomal route of MHC class I cross-presentation in bacteria-infected dendritic cells. Journal of immunology. 2013; 190:2791-2806.

46. Bell C, English L, Boulais J, Chemali M, Caron-Lizotte $\mathrm{O}$, Desjardins $\mathrm{M}$ and Thibault P. Quantitative proteomics reveals the induction of mitophagy in tumor necrosis factoralpha-activated (TNFalpha) macrophages. Molecular \& cellular proteomics. 2013; 12:2394-2407.

47. Li Y, Wang LX, Pang P, Twitty C, Fox BA, Aung S, Urba WJ and Hu HM. Cross-presentation of tumor associated antigens through tumor-derived autophagosomes. Autophagy. 2009; 5:576-577.

48. Li B, Lei Z, Lichty BD, Li D, Zhang GM, Feng ZH, Wan Y and Huang B. Autophagy facilitates major histocompatibility complex class I expression induced by IFN-gamma in B16 melanoma cells. Cancer immunology, immunotherapy. 2010; 59:313-321.

49. Gannage M and Munz C. MHC presentation via autophagy and how viruses escape from it. Seminars in immunopathology. 2010; 32:373-381.

50. Crotzer VL and Blum JS. Autophagy and its role in MHCmediated antigen presentation. Journal of immunology. 2009; 182:3335-3341.

51. Schmid D, Pypaert M and Munz C. Antigen-loading compartments for major histocompatibility complex class II molecules continuously receive input from autophagosomes. Immunity. 2007; 26:79-92.

52. Dengjel J, Schoor O, Fischer R, Reich M, Kraus M, Muller M, Kreymborg K, Altenberend F, Brandenburg J, Kalbacher H, Brock R, Driessen C, Rammensee HG and Stevanovic S. Autophagy promotes MHC class II presentation of peptides from intracellular source proteins. Proc Natl Acad Sci U S A. $2005 ; 102: 7922-7927$.

53. Li Y, Hahn T, Garrison K, Cui ZH, Thorburn A, Thorburn J, $\mathrm{Hu} \mathrm{HM}$ and Akporiaye ET. The vitamin E analogue alphaTEA stimulates tumor autophagy and enhances antigen cross-presentation. Cancer research. 2012; 72:3535-3545.

54. Jia W, Pua HH, Li QJ and He YW. Autophagy regulates endoplasmic reticulum homeostasis and calcium mobilization in T lymphocytes. Journal of immunology. 2011; 186:1564-1574.

55. Pua HH, Guo J, Komatsu M and He YW. Autophagy is essential for mitochondrial clearance in mature $\mathrm{T}$ lymphocytes. Journal of immunology. 2009; 182:40464055.

56. Parekh VV, Wu L, Boyd KL, Williams JA, Gaddy JA, Olivares-Villagomez D, Cover TL, Zong WX, Zhang $\mathrm{J}$ and Van Kaer L. Impaired autophagy, defective $\mathrm{T}$ cell 
homeostasis, and a wasting syndrome in mice with a $\mathrm{T}$ cellspecific deletion of Vps34. Journal of immunology. 2013; 190:5086-5101.

57. Willinger $\mathrm{T}$ and Flavell RA. Canonical autophagy dependent on the class III phosphoinositide-3 kinase Vps34 is required for naive T-cell homeostasis. Proceedings of the National Academy of Sciences of the United States of America. 2012; 109:8670-8675.

58. Borel S, Robert-Hebmann V, Alfaisal J, Jain A, Faure M, Espert L, Chaloin L, Paillart JC, Johansen T and BiardPiechaczyk M. HIV-1 viral infectivity factor interacts with microtubule-associated protein light chain 3 and inhibits autophagy. Aids. 2015; 29:275-286.

59. Bruno AP, De Simone FI, Iorio V, De Marco M, Khalili K, Sariyer IK, Capunzo M, Nori SL and Rosati A. HIV-1 Tat protein induces glial cell autophagy through enhancement of BAG3 protein levels. Cell cycle. 2014; 13:3640-3644.

60. Li C, Capan E, Zhao Y, Zhao J, Stolz D, Watkins SC, Jin $\mathrm{S}$ and $\mathrm{Lu} \mathrm{B}$. Autophagy is induced in CD4+ T cells and important for the growth factor-withdrawal cell death. Journal of immunology. 2006; 177:5163-5168.

61. Kumai T, Matsuda Y, Ohkuri T, Oikawa K, Ishibashi K, Aoki N, Kimura S, Harabuchi Y, Celis E and Kobayashi H. c-Met is a novel tumor associated antigen for T-cell based immunotherapy against $\mathrm{NK} / \mathrm{T}$ cell lymphoma. Oncoimmunology. 2015; 4:e976077.

62. Sakakura K, Takahashi H, Kaira K, Toyoda M, Oyama $\mathrm{T}$ and Chikamatsu K. Immunological significance of the accumulation of autophagy components in oral squamous cell carcinoma. Cancer science. 2015; 106:1-8.

63. Rao S, Tortola L, Perlot T, Wirnsberger G, Novatchkova M, Nitsch R, Sykacek P, Frank L, Schramek D, Komnenovic V, Sigl V, Aumayr K, Schmauss G, et al. A dual role for autophagy in a murine model of lung cancer. Nature communications. 2014; 5:3056.

64. Garg AD, Dudek AM and Agostinis P. Autophagydependent suppression of cancer immunogenicity and effector mechanisms of innate and adaptive immunity. Oncoimmunology. 2013; 2:e26260.

65. Clarke AJ, Ellinghaus U, Cortini A, Stranks A, Simon AK, Botto $M$ and Vyse TJ. Autophagy is activated in systemic lupus erythematosus and required for plasmablast development. Annals of the rheumatic diseases. 2015; 74:912-920.

66. Miller BC, Zhao Z, Stephenson LM, Cadwell K, Pua HH, Lee HK, Mizushima NN, Iwasaki A, He YW, Swat W and Virgin HWt. The autophagy gene ATG5 plays an essential role in B lymphocyte development. Autophagy. 2008; 4:309-314.

67. Conway KL, Kuballa P, Khor B, Zhang M, Shi HN, Virgin HW and Xavier RJ. ATG5 regulates plasma cell differentiation. Autophagy. 2013; 9:528-537.

68. Chanut A, Duguet F, Marfak A, David A, Petit B, Parrens M, Durand-Panteix S, Boulin-Deveza M, Gachard N,
Youlyouz-Marfak I, Bordessoule D, Feuillard J and Faumont N. RelA and RelB cross-talk and function in Epstein-Barr virus transformed B cells. Leukemia. 2014; 28:871-879.

69. Zhou M, Li W, Wen Z, Sheng Y, Ren H, Dong H, Cao $\mathrm{M}, \mathrm{Hu} \mathrm{HM}$ and Wang LX. Macrophages enhance tumor-derived autophagosomes (DRibbles)-induced B cells activation by TLR4/MyD88 and CD40/CD40L. Experimental cell research. 2015; 331:320-330.

70. Chen M, Hong MJ, Sun H, Wang L, Shi X, Gilbert BE, Corry DB, Kheradmand F and Wang J. Essential role for autophagy in the maintenance of immunological memory against influenza infection. Nature medicine. 2014; 20:503510.

71. Teng MW and Smyth MJ. Cancer. Can cancer trigger autoimmunity? Science. 2014; 343:147-148.

72. Wolchok JD and Chan TA. Cancer: Antitumour immunity gets a boost. Nature. 2014; 515:496-498.

73. Li H, Li Y, Jiao J and Hu HM. Alpha-alumina nanoparticles induce efficient autophagy-dependent cross-presentation and potent antitumour response. Nature nanotechnology. 2011; 6:645-650.

74. van den Boorn JG, Picavet DI, van Swieten PF, van Veen HA, Konijnenberg D, van Veelen PA, van Capel T, Jong EC, Reits EA, Drijfhout JW, Bos JD, Melief CJ and Luiten RM. Skin-depigmenting agent monobenzone induces potent T-cell autoimmunity toward pigmented cells by tyrosinase haptenation and melanosome autophagy. The Journal of investigative dermatology. 2011; 131:1240-1251.

75. Gabai VL and Shifrin VI. Feasibility analysis of p62 (SQSTM1)-encoding DNA vaccine as a novel cancer immunotherapy. International reviews of immunology. 2014; 33:375-382.

76. Wen Y, Graybill WS, Previs RA, Hu W, Ivan C, Mangala LS, Zand B, Nick AM, Jennings NB, Dalton HJ, Sehgal $\mathrm{V}$, Ram P, Lee JS, et al. Immunotherapy targeting folate receptor induces cell death associated with autophagy in ovarian cancer. Clinical cancer research : an official journal of the American Association for Cancer Research. 2015; 21:448-459.

77. Li Y, Wang LX, Pang P, Cui Z, Aung S, Haley D, Fox BA, Urba WJ and Hu HM. Tumor-derived autophagosome vaccine: mechanism of cross-presentation and therapeutic efficacy. Clinical cancer research. 2011; 17:7047-7057.

78. Garg AD, Dudek-Peric AM, Romano E and Agostinis P. Immunogenic cell death. Int J Dev Biol. 2015; 59:131-140.

79. Pol J, Vacchelli E, Aranda F, Castoldi F, Eggermont A, Cremer I, Sautes-Fridman C, Fucikova J, Galon J, Spisek R, Tartour E, Zitvogel L, Kroemer G and Galluzzi L. Trial Watch: Immunogenic cell death inducers for anticancer chemotherapy. Oncoimmunology. 2015; 4:e1008866.

80. Ramakrishnan R, Huang C, Cho HI, Lloyd M, Johnson J, Ren X, Altiok S, Sullivan D, Weber J, Celis E and Gabrilovich DI. Autophagy induced by conventional 
chemotherapy mediates tumor cell sensitivity to immunotherapy. Cancer research. 2012; 72:5483-5493.

81. Koks CA, Garg AD, Ehrhardt M, Riva M, Vandenberk L, Boon L, De Vleeschouwer S, Agostinis P, Graf N and Van Gool SW. Newcastle disease virotherapy induces long-term survival and tumor-specific immune memory in orthotopic glioma through the induction of immunogenic cell death. International journal of cancer. 2015; 136:E313-325.

82. Michaud M, Martins I, Sukkurwala AQ, Adjemian S, Ma Y, Pellegatti P, Shen S, Kepp O, Scoazec M, Mignot G, RelloVarona S, Tailler M, Menger L, et al. Autophagy-dependent anticancer immune responses induced by chemotherapeutic agents in mice. Science. 2011; 334:1573-1577.

83. Michaud M, Xie X, Bravo-San Pedro JM, Zitvogel L, White E and Kroemer G. An autophagy-dependent anticancer immune response determines the efficacy of melanoma chemotherapy. Oncoimmunology. 2014; 3:e944047.

84. Yuk JM, Shin DM, Song KS, Lim K, Kim KH, Lee SH, Kim JM, Lee JS, Paik TH, Kim JS and Jo EK. Bacillus calmette-guerin cell wall cytoskeleton enhances colon cancer radiosensitivity through autophagy. Autophagy. 2010; 6:46-60.

85. Zhu S, Cao L, Yu Y, Yang L, Yang M, Liu K, Huang J, Kang R, Livesey KM and Tang D. Inhibiting autophagy potentiates the anticancer activity of IFN1@/IFNalpha in chronic myeloid leukemia cells. Autophagy. 2013; 9:317327.

86. Levy J, Cacheux W, Bara MA, L'Hermitte A, Lepage P, Fraudeau M, Trentesaux C, Lemarchand J, Durand A, Crain AM, Marchiol C, Renault G, Dumont F, et al. Intestinal inhibition of $\operatorname{Atg} 7$ prevents tumour initiation through a microbiome-influenced immune response and suppresses tumour growth. Nat Cell Biol. 2015; 17:1062-1073.

87. Lin TJ, Liang WM, Hsiao PW, M SP, Wei WC, Lin HT, Yin SY and Yang NS. Rapamycin Promotes Mouse 4T1 Tumor Metastasis that Can Be Reversed by a Dendritic Cell-Based Vaccine. PLoS One. 2015; 10:e0138335.

88. Akalay I, Janji B, Hasmim M, Noman MZ, Andre F, De Cremoux P, Bertheau P, Badoual C, Vielh P, Larsen AK, Sabbah M, Tan TZ, Keira JH, et al. Epithelial-tomesenchymal transition and autophagy induction in breast carcinoma promote escape from T-cell-mediated lysis. Cancer research. 2013; 73:2418-2427.

89. Lin CW, Lo S, Hsu C, Hsieh CH, Chang YF, Hou BS, Kao YH, Lin CC, Yu ML, Yuan SS, Hsieh YC. T-cell autophagy deficiency increases mortality and suppresses immune responses after sepsis. PLoS One. 2014; 9:e102066.
90. Tittarelli A, Janji B, Van Moer K, Noman MZ and Chouaib S. The Selective Degradation of Synaptic Connexin 43 Protein by Hypoxia-induced Autophagy Impairs Natural Killer Cell-mediated Tumor Cell Killing. J Biol Chem. 2015; 290:23670-23679.

91. Liang X, De Vera ME, Buchser WJ, Romo de Vivar Chavez A, Loughran P, Beer Stolz D, Basse P, Wang T, Van Houten B, Zeh HJ, 3rd and Lotze MT. Inhibiting systemic autophagy during interleukin 2 immunotherapy promotes long-term tumor regression. Cancer research. 2012; 72:2791-2801.

92. Ratikan JA, Sayre JW and Schaue D. Chloroquine engages the immune system to eradicate irradiated breast tumors in mice. International journal of radiation oncology, biology, physics. 2013; 87:761-768.

93. Mezzaroba N, Zorzet S, Secco E, Biffi S, Tripodo C, Calvaruso M, Mendoza-Maldonado R, Capolla S, Granzotto M, Spretz R, Larsen G, Noriega S, Lucafo M, et al. New potential therapeutic approach for the treatment of B-Cell malignancies using chlorambucil/hydroxychloroquineloaded anti-CD20 nanoparticles. PloS one. 2013; 8:e74216.

94. Noman MZ, Janji B, Kaminska B, Van Moer K, Pierson S, Przanowski P, Buart S, Berchem G, Romero P, MamiChouaib $\mathrm{F}$ and Chouaib S. Blocking hypoxia-induced autophagy in tumors restores cytotoxic T-cell activity and promotes regression. Cancer Res. 2011; 71:5976-5986.

95. Baginska J, Viry E, Berchem G, Poli A, Noman MZ, van Moer K, Medves S, Zimmer J, Oudin A, Niclou SP, Bleackley RC, Goping IS, Chouaib S, Janji B. Granzyme B degradation by autophagy decreases tumor cell susceptibility to natural killer-mediated lysis under hypoxia. Proc Natl Acad Sci U S A. 2013; 110:17450-17455.

96. Viry E, Baginska J, Berchem G, Noman MZ, Medves S, Chouaib S, Janji B. Autophagic degradation of GZMB/ granzyme B: a new mechanism of hypoxic tumor cell escape from natural killer cell-mediated lysis. Autophagy. 2014; 10:173-175.

97. Enzenmuller S, Gonzalez P, Debatin KM and Fulda S. Chloroquine overcomes resistance of lung carcinoma cells to the dual PI3K/mTOR inhibitor PI103 by lysosomemediated apoptosis. Anti-cancer drugs. 2013; 24:14-19.

98. Maycotte P, Aryal S, Cummings CT, Thorburn J, Morgan MJ and Thorburn A. Chloroquine sensitizes breast cancer cells to chemotherapy independent of autophagy. Autophagy. 2012; 8:200-212. 